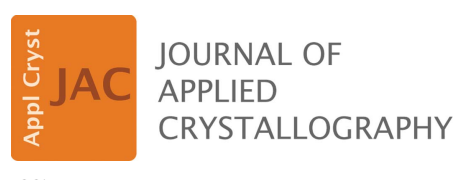

ISSN 1600-5767

\section{On the 80th birthday of Professor (retired) Dr Dr h.c. Peter Paufler}

\author{
Dirk C. Meyer ${ }^{\mathrm{a} *}$ and Ekkehart Tillmanns ${ }^{\mathrm{b}}$
}

anstitute of Experimental Physics, Centre of Efficient High-Temperature Substance Conversion, TU Bergakademie Freiberg, Leipziger Strasse 23, D-09599 Freiberg, Germany, and ${ }^{\mathbf{b}}$ University of Vienna, Vienna, Austria. *Correspondence e-mail: dirk-carl.meyer@physik.tu-freiberg.de

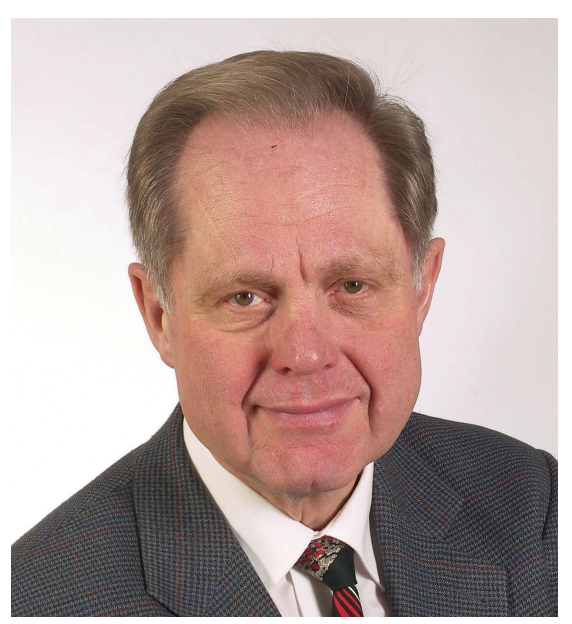

On the occasion of his 80th birthday on 18 February 2020, the authors would like to congratulate Professor (retired) Dr Dr h.c. Peter Paufler on behalf of numerous colleagues and students and wish him all the best for the future.

Peter Paufler was born in Dresden, where he began his studies of physics at the Technical University in 1958. In his diploma thesis in 1963 he dealt with the growth of single crystals of intermetallic compounds. His doctorate followed in 1967 and his habilitation in 1971. As a co-worker of Gustav E. R. Schulze he made fundamental contributions to our knowledge of the plastic behaviour of the Laves phase $\mathrm{MgZn}_{2}$. It was also his mentor and scientific teacher G. E. R. Schulze who shielded Peter Paufler from various politically motivated attacks and thus helped him to enter a university teaching career, which would probably not have been possible under the circumstances at that time.

From 1963 onwards Peter Paufler was a research assistant and senior assistant at the same institute. During this period he also dealt with questions on the systematics of crystal structures of intermediate phases in cooperation with Professor Schulze. At the same time, he worked temporarily at the Nuclear Research Centre in Grenoble and at the Institute of Nuclear Research in Dubna, as well as in 1971/1972 at the Faculty of Physics of Moscow State University. In 1970 Peter Paufler was appointed as a lecturer for experimental physics, and in 1973, after the retirement of Professor Schulze, he took over the leadership of the teaching team for solid state physics, which was responsible for the education of all physics students at the TU.

In 1968 Peter Paufler became a member of the Association for Crystallography of the GDR (VFK), in which he soon became actively involved. In 1972 he became chairman of the working group for lattice physics, from 1974 he was a member of the board of the VFK and the National Committee for Crystallography of the GDR, and from 1983 to 1985 he was chairman of the VFK. In 1978 Peter Paufler was appointed to the Chair of Crystallography at the University of Leipzig as successor of $\mathrm{H}$. Neels. This position was connected with the management of the Institute of Crystallography, Mineralogy and Material Sciences. During his work he concentrated especially on the investigation of semiconducting III-V compounds. In 1992 he accepted a call to the Chair of Crystallography at the TU Dresden until he retired in 2006. Apart from his participation in university committees and national and international crystallographic organizations, Peter Paufler has devoted special attention to teaching in both Leipzig and Dresden. His students and those who attended his lectures have always emphasized that he was very successful in this field.

His scientific work comprises more than 200 publications. Peter Paufler is the author of several textbooks, of which the Physikalische Kristallographie published in 1986 deserves special mention, a book which has familiarized generations of students with the basics of 
crystal physics and the physical properties of crystals. He was Book Review Editor for IUCr Journals from 2004 to 2014.

Peter Paufler is a member of a number of scientific associations. He was instrumental in the founding of the German Society for Crystallography (DGK), the successor organization of VFK and the Working Group for Crystallography (AGKr). He was a member of the board and chairman and was appointed honorary member in 2014. In 2006 Peter
Paufler became an honorary member of the German Mineralogical Society (DMG), in which he also served as chairman. In the same year the University of Leipzig awarded him an honorary doctorate; in 1993 he was elected as member of the German Academy of Science Leopoldina, and since 1998 he has also been a member of the Saxon Academy of Sciences in Leipzig.

The authors wish Peter Paufler many more fulfilled years in life and science. 